\title{
Sobre los inicios de una trayectoria literaria: el caso de César Aira en publicaciones periódicas
}

María Belén Riveiro*

Artículo de investigación sobre las condiciones de posibilidad que habilitan la emergencia de una posición disruptiva, como la de César Aira, dentro del campo literario de Buenos Aires en los años ochenta a través del estudio de su participación en publicaciones periódicas.

Recibido: 1 de julio de 2020

Evaluado: 15 de marzo de 2021

Aceptado: 16 de marzo de 2021

Publicado: 1 de julio de 2021

Citar como:

Riveiro, M. (2021). Sobre los inicios de una trayectoria literaria: el caso de César Aira en publicaciones periódicas. Hallazgos, 18(36), 179-214.

https://doi.org/10.15332/2422409X.5975

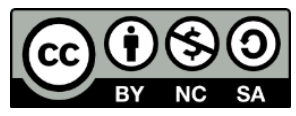

\section{Resumen}

Desde una mirada sociológica, este artículo estudia la literatura para construirla como una práctica social. Tomo el caso de César Aira para reconstruir los comienzos de su carrera, cuando se enfrenta a diversos obstáculos. Me pregunto por las condiciones que posibilitaron la emergencia de su figura, porque este caso me permite formular

\footnotetext{
* Doctora en Ciencias Sociales por la Universidad de Buenos Aires. Docente de la misma casa de estudios y becaria posdoctoral de Conicet con lugar de trabajo en el Instituto de Investigaciones Gino Germani (FSoc-UBA).

Correo electrónico: mbriveiro@sociales.uba.ar

ORCID: https://orcid.org/0000-0002-0499-9320
}

Hallazgos

ISSN: 1794-3841 | e-ISSN: 2422-409X | DOI: https://doi.org/10.15332/2422409X

Vol. 18 N.o 36| julio-diciembre del 2021 
interrogantes por las posibilidades que habilitan prácticas disruptivas. Uno de los modos de aprehender este proceso es mediante el estudio de las publicaciones periódicas, en las que encuentro que Aira colabora con artículos y reseñas desde 1981, cuando circula su primer libro: Ema, la cautiva. Analizo los artículos que aparecen en publicaciones periódicas y las características de las revistas y suplementos donde aparecen, las zonas del campo y el circuito de los que participan, puesto que son mediaciones que forman parte del hecho literario. El trabajo documental permite proponer que es durante el periodo de apertura política y cultural que acompaña a la transición democrática argentina de 1983 cuando Aira encuentra, en zonas marginales del campo literario, los espacios que habilitan una posición como la suya, que, recién años después, recibirá la atención de numerosos actores del campo y experimentará una creciente consagración.

Palabras clave: César Aira; Campo literario; Publicaciones periódicas; Sociología de la literatura; Transición democrática argentina.

\section{On the beginnings of a literary trajectory: the case of César Aira in periodicals}

\section{Abstract}

This article studies literature, from a sociological viewpoint, in order to construct it as a social practice. I take the case of César Aira to reconstruct the beginnings of his career, when he faces various obstacles. I wonder about the conditions that made possible the emergence of his figure, because this allows me to ask questions about the possibilities that enable disruptive practices. One of the ways to apprehend this process is through the analysis of periodicals where Aira published articles and reviews since 1981, when his first book (Ema, the Captive, Editorial de Belgrano) was published. I analyze the articles that appear in periodicals and the characteristics of the journals and inserts where they appear, the areas of the field and the circuits of those who participate, since they are mediations that are part of the literary fact. The 
documentary work allows to suggest that it is during the period of political and cultural opening with Argentine democratic transition of 1983 when Aira finds, in marginal areas of the literary field, the spaces that enable a position like his, which, only years later, will receive the attention of many agents in the field and experience a growing recognition.

Keywords: César Aira; Literary field; Periodicals; Sociology of literature; Argentine democratic transition.

\section{Sobre o início de uma carreira literária: o caso de César Aira em publicações periódicas}

\section{Resumo}

Do ponto de vista sociológico, este artigo estuda a literatura para construí-la como uma prática social. Utilizo o caso de César Aira para reconstruir o início de sua carreira, quando ele enfrentou vários obstáculos. Pergunto-me sobre as condições que possibilitaram o surgimento de sua figura, pois este caso me permite formular interrogantes pelas possibilidades que viabilizam práticas disruptivas. Uma das formas de apreender esse processo é por meio do estudo de publicações periódicas, nas quais descobri que Aira colabora com artigos e resenhas desde 1981, quando seu primeiro livro foi publicado (Ema, la cautiva, Editorial de Belgrano). Analiso os artigos que aparecem em periódicos e as características das revistas e suplementos onde aparecem, as áreas do campo e o circuito em que participam, visto que são mediações que fazem parte do fato literário. O trabalho documental permite propor que é durante o período de abertura política e cultural que acompanha a transição democrática argentina de 1983 quando Aira encontra, em zonas marginalizadas do campo literário, os espaços que possibilitam uma posição como a sua, que, só anos depois, receberá a atenção de numerosos atores do campo e experimentará uma consagração crescente. 
Palavras-chave: Cesar Aira; Campo literário; Publicação periódicas;

Sociologia da literatura; Transição democrática argentina.

\section{Introducción}

Comienzo este artículo con dos panoramas contrastantes. El primero: en torno a la figura de César Aira se repiten dos características. En primer lugar, se destaca el volumen de su obra, que para 2018 supera los cien títulos: "Aira es una de las figuras más prolíficas y originales de la actual narrativa argentina" (Sperling, citada en Aira, 1984, p. 1); "Uno de los principales problemas de César Aira es esa insoportable inclinación a lo excesivo: demasiados libros, demasiados admiradores incondicionales, incluso demasiadas (a pesar de ser tan pocas) declaraciones y afirmaciones sobre la propia obra" (Galperín, 1992, p. 14); "este prolífico escritor de culto" ("Un banquete para la lectura", 2005), "Usted es un escritor muy prolífico" (Dapelo, citado en Aira, 2007), las citas podrían seguir. En segundo lugar, tal como identifico en una primera reflexión sobre este tema (Riveiro, 2018), se lo construye como un escritor que no da entrevistas: "Aira aceptó charlar con 3 puntos rompiendo su costumbre de no dar reportajes" (Berti, citado en Aira, 2001); "Desde hace años, Aira (Pringles, 1949), autor de más de sesenta libros entre novelitas, teatro y ensayos, no concede entrevistas en su país" (Garzón, citado en Aira, 2004); "De pasada, César explica por qué no da entrevistas en su país" (Aiyén, citado en Aira, 2005); "César Aira (Coronel Pringles, 1949) apenas concede entrevistas en su país" (Rodríguez Marcos, citado en Aira, 2016) ${ }^{1}$.

Para el segundo panorama nos tenemos que retrotraer a los años setenta y ochenta. Durante toda la década de los setenta Aira intenta publicar sus manuscritos. Sin embargo, solo encuentra negativas por parte de las

\footnotetext{
${ }^{1}$ En Riveiro (2019) discuto este sentido cristalizado en relación con Aira y reconstruyo los modos en que se presenta en público en entrevistas entre 1981 y 2001.
}

Hallazgos

ISSN: 1794-3841 | e-ISSN: 2422-409X | DOI: https://doi.org/10.15332/2422409X

Vol. 18 N.0 36| julio-diciembre del 2021 
editoriales que se pueden resumir en el "Decile a tu amiguito que esto no va" (Strafacce, 2008, p. 340), que comenta Juan Granica cuando Tamara Kamenszain, encargada de armar una colección de jóvenes narradores para la editorial Granica, le presenta Moreira de Aira. Y cuando en los años ochenta sí comienzan a publicar sus libros, no solo da numerosas entrevistas - encuentro más de una veintena-, sino que realiza allí afirmaciones contundentes que llamarán la atención. En la revista Pie de Página comenta "yo nunca usaría la literatura para pasar por una buena persona" (Aira, 1982, p. 2) ${ }^{2}$.

César Aira es un escritor que nació en 1949 (Coronel Pringles, provincia de Buenos Aires, Argentina). Sus primeros libros comenzaron a circular en 1981. De acuerdo con un rastreo de indicadores convencionales de prestigio que datan de fines de la década de los noventa y comienzos del siglo XXI, tal como expongo en un artículo anterior (Riveiro, 2019), Aira cuenta con numerosos premios ${ }^{3}$, es un autor muy traducido ${ }^{4}$, ocupa un

\footnotetext{
2 En este artículo, en tanto incorporo la voz de los propios actores y en particular la de Aira (cuestión que elaboro en el apartado sobre teoría y metodología), distingo las citas de Aira que corresponden a textos de publicaciones periódicas, empleando la letra "i" enseguida de su apellido, con el fin de diferenciarlas de los fragmentos de entrevistas (véase el apartado de referencias "Textos de Aira en publicaciones periódicas" al final de este artículo).

${ }^{3}$ Por ejemplo, en 1989 es finalista del concurso Clarín-Aguilar por La liebre. Esta novela recibe el premio Boris Vian en 1992. Este premio lo otorgan sus pares, es decir, otros escritores que lo denominan como "antipremio" ("Un antipremio a la poesía", 1987 , p. 9), dado que contrasta con los galardones de instituciones oficiales como el antes citado premio Clarín. En 2001, recibe una mención del premio Konex a la novela del quinquenio 1989-1993. En 1996, gana la Beca Guggenheim. En 2014, recibe el Premio Roger Caillois en Francia; y en 2016, el Premio Iberoamericano de Narrativa Manuel Rojas en Chile.

${ }^{4}$ Los datos recopilados sobre traducciones de libros de Aira en las bases de datos WorldCat, Index Translationum de la Unesco, la biblioteca de la Alianza Francesa de Buenos Aires, la biblioteca personal de Ricardo Strafacce y la página de Facebook Todo Aira indican que los libros aparecieron traducidos a diecinueve idiomas. En 1988, aparece la primera traducción y en 2017 se superan las cien traducciones.
}

Hallazgos

ISSN: 1794-3841 | e-ISSN: 2422-409X | DOI: https://doi.org/10.15332/2422409X

Vol. 18 N.o 36| julio-diciembre del 2021 
lugar central en editoriales ${ }^{5}$ y la crítica académica y aquella en publicaciones periódicas son muy positivas en torno a su obra ${ }^{6}$.

Con este creciente prestigio ${ }^{7}$ se comienzan a cristalizar sentidos alrededor de su figura y obra como la noción de prolífico y de escritor "silencioso" -tal como él mismo propone: "soy extraordinariamente silencioso" (Aira, 1991, p. 3) -, que se suelen reflejar de manera retrospectiva en toda su trayectoria. De este modo, se desdibujan las imágenes contrastantes que mencioné antes y se obtura la posibilidad de acceder a cómo se fue transformando la posición de Aira en el campo, así como sus prácticas. El abordaje que propongo para este artículo permite evitar la ilusión biográfica que halla en la biografía una totalidad coherente; en otras palabras, una línea unidireccional en la que es posible identificar elementos que, al modo de augurios, explican cómo se llega a ser la figura que finalmente se es (Bourdieu, 2005). Este análisis permite no solo problematizar sentidos comunes y recuperar facetas soslayadas de una trayectoria, sino también enriquecer nuestro conocimiento de una obra y de un escritor.

\footnotetext{
${ }^{5}$ En 2011, la editorial Emecé crea la Biblioteca César Aira al igual que Literatura Random House en 2015. En 2019, la editorial de capitales nacionales Blatt \& Ríos presenta su Biblioteca César Aira y reedita títulos con una estética homogénea. ${ }^{6}$ Una consulta de publicaciones periódicas de Buenos Aires entre 1981 y 2001 me permite encontrar reseñas de todos los libros de Aira al momento en que se publican - salvo excepciones como las de Moreira, distribuida años después de su impresión, Nouvelles impressions du Petit Maroc, publicada en Francia, y El infinito-. El interés de numerosos artículos de revistas especializadas y tesis dedicadas a la obra del autor se apoyan en el acuerdo sobre su pertinencia (Astutti, 1997; Montaldo, 1998; Estrín, 1999; Remon-Raillard, 1999; Fernández, 2000; Laddaga, 2001; Contreras, 2002; García, 2006).

7 Cabe aclarar que la consagración no es un fenómeno simple de aprehender, sobre todo en un campo literario con instituciones y autoridades débiles y fluctuantes como el de Buenos Aires (Sigal, 1991; Rubinich, 1999). Sigo a Ana Boschetti (2014) en su reflexión sobre la centralidad y las posiciones de dominación en los campos literarios y artísticos. Por eso la hipótesis de la centralidad que Aira ejerce adquiere fuerza al pensar en sus efectos en el campo literario de Buenos Aires mediante el estudio de la recepción de la crítica, de su trayectoria editorial y de los modos en que se presenta en público como escritor. En Riveiro (2020) reconstruyo su trayectoria y las posiciones que ocupa a lo largo de los años en el campo literario de Buenos Aires.
}

Hallazgos

ISSN: 1794-3841 | e-ISSN: 2422-409X | DOI: https://doi.org/10.15332/2422409X

Vol. 18 N.o 36| julio-diciembre del 2021 
Este artículo formula la pregunta por los comienzos de la trayectoria de Aira para dar cuenta de las condiciones de posibilidad de la emergencia de una singularidad como la suya que, en sus comienzos, no encontraba espacios donde participar. Para responder a ello, recorto el objeto de estudio en la participación de Aira en publicaciones periódicas. El abordaje de este estudio es sociológico, por lo que el análisis de la literatura no se circunscribe a lo textual ni a cuestiones intrínsecas al objeto, sino a sus relaciones con otros elementos y procesos y, en particular, a mediaciones entre el objeto literario y los hechos sociales. En esta oportunidad me detengo en textos que Aira escribe para publicaciones periódicas y que permanecen poco explorados ${ }^{8}$. Me pregunto por los espacios que se abren para la propuesta de Aira y por los modos en que se comienza a presentar en público. ¿En qué publicaciones comienza a colaborar Aira? ¿Qué otros escritores, críticos y periodistas participan allí? ¿En qué zonas del campo podemos ubicar estas publicaciones? ¿Cómo son aquellos espacios habilitados para la propuesta literaria de Aira?

\section{Teoría y metodología}

Este artículo se inscribe en la sociología de la literatura y en la propuesta de Pierre Bourdieu (2007) que propone dar cuenta de las mediaciones sociales que enriquecen nuestro conocimiento sobre objetos del arte y la literatura. En principio, se trata de una mirada histórica y relacional. La propuesta consiste en ir más allá de la división disciplinar entre historia, sociología y estudios literarios. Así, incorporo la instancia de la reconstrucción histórica que permite reinsertar el objeto de estudio en su contexto y con sus condiciones de posibilidad (Bourdieu y Wacquant, 1995). Aquello que Loïc Wacquant llama "relacionismo metodológico"

\footnotetext{
${ }^{8}$ En abril de 2021 la editorial Literatura Random House publicó una compilación de algunos de estos textos titulada La ola que lee. Artículos y reseñas (1981-2001), cuya edición y prólogo estuvieron a mi cargo.
}

Hallazgos

ISSN: 1794-3841 | e-ISSN: 2422-409X | DOI: https://doi.org/10.15332/2422409X 
(Bourdieu y Wacquant, 1995, p. 25) se define en contraposición con una mirada que busca en lo intrínseco del objeto la explicación. Las posiciones de los actores en el campo se definen según el resto de las posiciones. Resulta necesario conocer a aquellos autores y producciones que la historia de la literatura no conserva, dado que circunscribirse a aquellos que sí se consagran y a los sentidos cristalizados al momento del éxito supone el riesgo de replicar en el análisis los efectos de las dinámicas históricas y volver a olvidar a esos mismos escritores y posiciones (Bourdieu, 2005, pp. 112-113).

Conceptualizo la literatura como una práctica social que, como toda práctica, construye y también recibe condicionamientos. En la esclarecedora introducción a la teoría de la acción de Bourdieu que cité antes, Wacquant esquematiza dos momentos del análisis. Por un lado, un alejamiento de las representaciones cotidianas para construir un espacio de posiciones y recursos que definen coerciones externas y límites: el campo; por el otro, la reintroducción de la experiencia de los agentes, de sus categorías de apreciación y percepción, en otros términos, sus tomas de posición: sus disposiciones (Bourdieu y Wacquant, 1995, p. 20). Wacquant entiende que, escapando de los binarismos, la apuesta de Bourdieu es por el estudio de la relación de complicidad ontológica entre el agente social y el mundo. El foco no está en ninguno de los términos sino en las relaciones.

Un concepto clave que media entre lo literario y lo social es el de campo. Bourdieu (2005) toma esta noción de la física para definirlo como campo de fuerzas con dos polos que se atraen y repelen. El campo, para este autor, está constituido por posiciones con un peso funcional específico que se define en relación con las demás posiciones. Se trata de espacios estructurados de posiciones y tomas de posición entre las cuales existe un espacio de los posibles. En un recorte sincrónico es posible estudiar de 
forma independiente las características de las posiciones de sus ocupantes que constituyen un espacio jerarquizado, dada una desigual distribución del capital específico que da lugar a relaciones de competencia por el monopolio de la legitimidad cultural (la consagración y el poder de consagrar) (Bourdieu, 2005). Aquel capital es "energía física social" (Bourdieu y Wacquant, 1995, p. 104). Se trata de un capital que no se restringe a las prácticas socialmente reconocidas como económicas, sino que corresponde a diferentes especies - económico, social, cultural, simbólico (especial porque es cualquier especie de capital, pero reconocido como legítimo)- y estados (incorporado, objetivado).

También es un espacio de relaciones de cooperación. Quienes participan en un campo comparten una cierta complicidad, es decir, tienen intereses y una creencia en común (Bourdieu, 2005). Se valora el mero hecho de participar y, de allí, la inversión en el juego social (Bourdieu, 2007). Bourdieu reflexiona sobre el concepto de illusio para dar cuenta de la creencia en aquello que está en juego en cada campo. Contrapone la illusio a la noción de ataraxia porque "se refiere al hecho de estar involucrado, de estar atrapado en el juego y por el juego" (Bourdieu y Wacquant, 1995, p. 80).

Otra de las principales categorías en este artículo es la de la trayectoria. Se trata de las diversas posiciones singulares que ocupan los actores en el espacio social, en este caso particular, el campo literario a lo largo de los años (Bourdieu, 2005, p. 384). El estudio de la trayectoria de un actor busca evitar la reconstrucción de un proyecto originario que integre toda la verdad objetiva de una condición, de una historia, de una biografía y de una obra, y que defina la imagen inaprehensible del genio o del carisma. La pregunta es por las condiciones de producción de esa singularidad. En este artículo contribuyo a responder este interrogante con el estudio de la 
producción de artículos, reseñas y ensayos de Aira que aparecen en publicaciones periódicas.

Antes de pasar a detallar la metodología implementada, cabe aclarar una cuestión relativa al modo en que conceptualizo el caso empírico. Estudiar a Aira, desde una mirada sociológica, me permite indagar en hechos que desbordan su individualidad. Por ello preciso diferenciar a los individuos empíricos de los científicamente construidos (Martínez, 2007). En este trabajo, cuando menciono la trayectoria de Aira, me refiero a un caso particular dentro del universo de lo posible, una singularidad que no constituye una probabilidad calculable, sino una posibilidad razonable. Los nombres propios, en cuanto individuos construidos en la investigación,

[...] ya no deben ser aquí leídos como etiquetas que señalan seres humanos concretos, en la riqueza de la totalidad de su vida histórica, sino palabras para nombrar un conjunto limitado de propiedades seleccionadas según las necesidades de la investigación, y explícitamente definidas y convertidas en variables, variables que adquieren su valor en el sistema correspondiente de diferencias, y obtienen su significación del conjunto de relaciones explícitamente definidas, cuyos nudos están representados por esas palabras. (Martínez, 2007, p. 243)

A fin de reconstruir las distintas posiciones que conforman la trayectoria de Aira, en este artículo me enfoco en identificar su participación en publicaciones periódicas. Este tipo de producciones está incluido en algunos de los estudios sobre el autor, como en la tesis de Sandra Contreras (2002); una fuente más para la conformación de hipótesis. Julio Premat (2005) también trabaja sobre la figura de autor de Aira mediante la matriz de la teoría literaria que, como comenta, se ve desafiada ante su literatura, dado que pone "en duda los criterios y mecanismos de lectura y evaluación estética” (p. 43). Para la confección de este artículo no solo me 
restrinjo a los textos, sino que también abordo los espacios donde se publican. Para rastrear este tipo de participación de Aira realizo trabajo de archivo. La lectura de publicaciones periódicas me permite hallar textos e intervenciones de Aira pasados por alto en otros estudios, y que permanecen poco explorados ${ }^{9}$.

El recorte temporal de este trabajo de archivo y del artículo abre en 1981 porque es cuando circulan por primera vez libros de Aira (Ema, la cautiva, Editorial de Belgrano, Buenos Aires; Moreira, Achával solo, Buenos Aires [1975]). El corte temporal concluye en 1990, cuando rastreo indicadores en los que se muestra una creciente valoración de la figura de Aira, como mencioné en la introducción del artículo. El recorte espacial es en la ciudad de Buenos Aires porque allí reside Aira y es donde comienza a publicar libros y artículos. Para realizar la revisión documental confecciono un corpus de publicaciones periódicas con libros y artículos (Otero, 1990; Salvador et ál., 1996; Román, 1997; Chacón y Fondebrider, 1998; Tarcus, 2007; Hernaiz, 2012). Allí encontré listados de publicaciones argentinas dedicadas a la literatura o que abocan alguna sección a este tipo de producciones.

\section{Condiciones de posibilidad para la publicación y las publicaciones periódicas}

En los comienzos de los ochenta, la presión del aparato represor y censor de la dictadura militar de 1976 comienza a debilitarse (Franco, 2018). Con anterioridad a 1983, cuando asume el gobierno elegido de manera democrática, en el campo literario argentino comienzan a proliferar las críticas a problemas de índole cultural e incluso relativos a lo político (de Diego, 2007).

\footnotetext{
${ }^{9}$ Confeccioné un listado de los textos de Aira en publicaciones periódicas que se puede consultar en Strafacce (2018).
}

Hallazgos

ISSN: 1794-3841 | e-ISSN: 2422-409X | DOI: https://doi.org/10.15332/2422409X 
Una de las formas en que se manifiesta esta apertura es la creación de editoriales de capitales nacionales y de catálogos y colecciones dedicadas a autores argentinos, sobre todo de escritores prohibidos o exiliados (Saítta, 2004; de Diego, 2007). Legasa abre la Colección Narradores Argentinos; la editorial de Belgrano crea la colección Narradores Argentinos Contemporáneos, dirigida por Osvaldo Pelletieri, y el Centro Editor de América Latina presenta la colección Capítulo/Las Nuevas Propuestas, dirigida por Susana Zanetti. Allí se habilitan debates sobre los cánones de la literatura argentina en un movimiento de revisión y crítica (Saítta, 2004). Si bien la publicación de los libros censurados y de aquellos editados en el exilio copan los catálogos, quedan intersticios para los inéditos. Después de diez años de recibir rechazos editoriales (Riveiro, 2020), Aira encuentra la posibilidad de editar sus manuscritos. El primer libro de Aira, Ema, la cautiva (1981) aparece en la editorial de Belgrano en la colección Narradores Argentinos Contemporáneos.

Otra de las formas que adopta esta apertura en el campo literario es la proliferación de publicaciones fomentada por el debilitamiento del aparato censor (Patiño, 1997). Algunas de ellas, como Punto de Vista (1978-2008) y Nova Arte (1978-1980), se fundan en pleno periodo represivo, y los autores y editores deben tomar medidas como adoptar seudónimos para publicar sus textos. Otras de ellas, como El Porteño (1982-1992), se crean cuando se comienza a sentir la posibilidad de una transición democrática. Ciertas lecturas conceptualizan estas publicaciones como "revistas subterráneas" porque construyen una contracultura frente a la impuesta por la dictadura con distintas propuestas: la cultura beat (Antimitomanía, 1974-1978), el compromiso sartreano (El Ornitorrino, 1977-1986), el surrealismo (Poddema, 1979-1980; Signo Ascendente, 1980-1982), la tradición de partidos de izquierda (Nudos, 1978-1992; Propuesta, 19771980), la nueva izquierda (Ulises, 1978-1979; Sitio, 1981-1987) y la poesía 
(Xul. Revista de Poesía, 1980-1997; Último Reino, 1979-1998)

(Margiolakis, 2014).

Estas publicaciones albergan "intensos debates y acaloradas polémicas", no solo sobre la reconstrucción de la cultura, sino también sobre la reconfiguración del campo intelectual, del literario e incluso sobre la política y la recuperación de la democracia (de Diego, 2007, p. 202). Más allá de sus diferentes características, las publicaciones comparten una disposición para prestar atención a propuestas que ingresan de manera reciente al campo en el contexto del reordenamiento y la redefinición del canon literario (de Diego, 2007). Esto permite dar cuenta de la habilitación para producciones como las de Aira en franco contraste con los rechazos editoriales de los setenta.

Ahora bien, específicamente ¿̇cómo son aquellos espacios habilitados para los textos que Aira escribe en los años ochenta como un autor recientemente editado? No resulta una coincidencia que los primeros artículos que circulan de Aira al momento en que está por convertirse en un escritor editado sean a través de una revista que también depende de la Universidad de Belgrano: la revista Vigencia. En general, los artículos y las reseñas que Aira escribe en estos años no aparecen en revistas especializadas como podría esperarse de un escritor cuya propuesta refuerza las particularidades de lo literario. Más adelante analizaré las publicaciones que ocupan las zonas centrales del campo en estos años. En los ochenta, la mayoría de los textos de Aira se publican en Vigencia, El Porteño, Creación y Fin de Siglo. Salvo Vigencia, todas ellas son publicaciones creadas en este periodo de creciente apertura y transición democrática. Vigencia se funda en 1977, El Porteño en 1982, Creación en 1986 y Fin de Siglo en 1987. Ninguna de ellas se especializa en literatura, sino en política y temas de lo que identifican como interés general. Incluyo imágenes que muestran cómo estos temas son los predominantes en las 
tapas de algunas de estas revistas para ilustrar la importancia de la materialidad de los espacios de los que participan los escritores (figuras 1 a 4$)$.

Figura 1. Tapa de Vigencia, $\mathrm{n} .^{\circ} 51$, agosto de 1981.

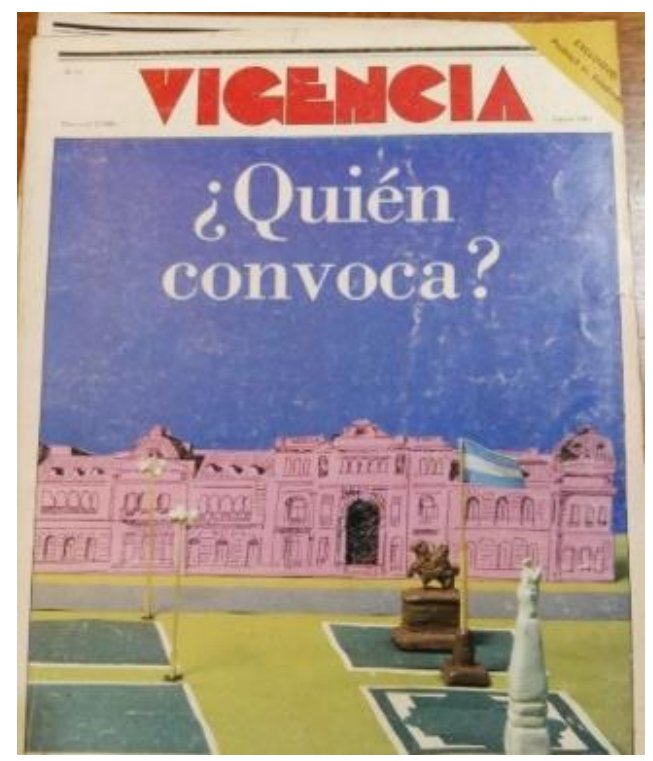

Fuente: Hemeroteca de la

Biblioteca Nacional Mariano

Moreno.
Figura 2. Tapa de El porteño, año V, n. ${ }^{\circ} 51$, marzo de 1986.

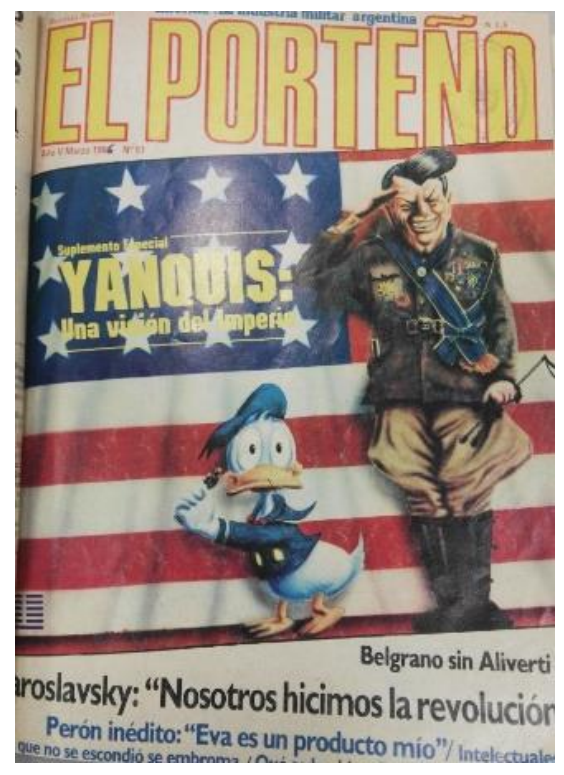

Fuente: Hemeroteca del Congreso de la Nación. 
Figura 3. Tapa de Creación, año 1, n. ${ }^{\circ}$, julio de 1986.

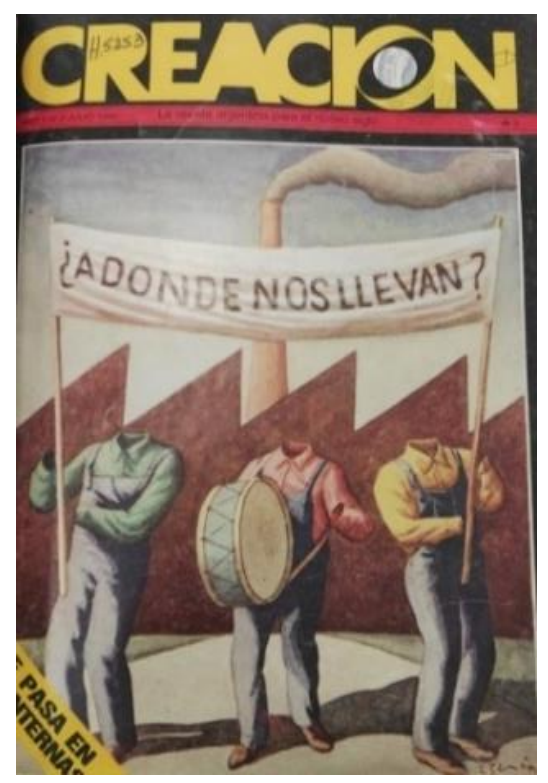

Fuente: Hemeroteca del

Congreso de la Nación.
Figura 4. Tapa de Fin de siglo, n. ${ }^{\circ}$

1, julio de 1987

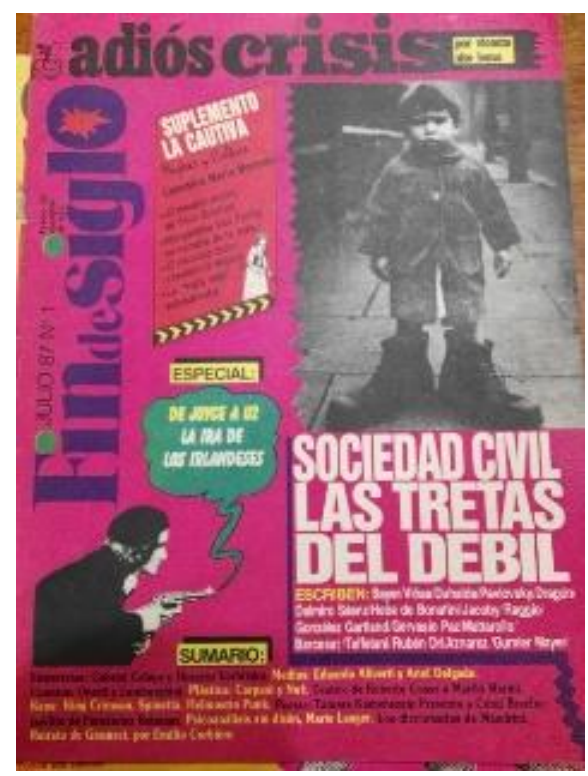

Fuente: Centro de

Documentación e

Investigación de la Cultura de Izquierdas.

Vigencia es una publicación de la Editorial de Belgrano que tiene secretarios de redacción en política y economía, cultura y tiempos modernos, y arte. En esta su segunda época apuesta a una tirada grande, 20 ooo ejemplares, con el fin de llegar a un público amplio y, a la vez, sostener su anclaje académico, por sus colaboradores y los espacios destinados a las actividades universitarias, cuyo público es mucho más acotado (Servelli, 2020). Su redacción está compuesta por periodistas formados en publicaciones que renovaron el periodismo en los sesenta y setenta (Servelli, 2020, p. 6) como Primera Plana (1962-1973) y La Opinión (1971-1981).

Gabriel Levinas crea El Porteño y la dirige hasta 1985, tras lo cual una cooperativa de periodistas toma el mando. Esta revista comienza a indagar 
en cuestiones políticas, económicas y culturales - como la psiquiatría, la ecología, los pueblos originarios, el autoritarismo-. Por esos años $E l$ Porteño logra "una circulación masiva sin que ello significara mantener los estilos y temas de los medios tradicionales. Había un público amplio para eso y la revista logró captarlo" (Warley, 1993, p. 205).

Creación la edita Jorge Garfunkel, quien financia El Porteño antes de fundar esta revista - uno de los modos en que se hacen visibles los lazos de sociabilidad que unen a estas publicaciones-. El primer número presenta la revista como una "propuesta de diálogo al servicio de la modernización" (Editor, 1986, p. 1). Las notas de tapa de esta revista muestran de manera clara sus ejes centrales alejados de lo estrictamente literario: el traslado de la capital federal (n. $\left.{ }^{\circ} 1\right)$, el sindicalismo (n. $\left.{ }^{\circ} 2\right)$, las relaciones internacionales de Argentina ( $\left(.^{\circ} 3\right.$ ) y las fuerzas armadas y los servicios de inteligencia (n. $\left.{ }^{\circ} 4\right)$. Solo salen cuatro números.

Fin de Siglo se construye como continuadora de Crisis (cuya segunda época cierra en 1987 tras haber vuelto a editarse un año antes; en octubre de 1987 inicia la tercera época), en tanto sigue "creyendo en la belleza", en que "la primera obligación de un intelectual es comprometerse en la defensa de la condición humana", en "construir" una sociedad "más justa y solidaria" y en que "la cultura es un arma decisiva para que nuestra obstinación se cruce algún día con la historia” (Zito Lema, 1987, p. 2). El tono de la revista es una apuesta "a la consolidación de un frente de izquierdas en lo político, bajo una apelación: 'unidad en la diversidad' [...] La revista toda tiene una impronta que abrevará, años después, en Locas. Cultura y Política, la revista de las Madres [de Plaza de Mayo]" (Korn, 2019).

Estas publicaciones si bien no se enfocan en particular en la literatura, sí comparten una disposición por la búsqueda de novedades en sintonía con el clima en que se insertan de primavera democrática y "destape" 
(Milanesio, 2019): una tendencia cultural que es una metáfora de la libertad, la modernidad, la adultez y el disfrute de la vida que explota como respuesta al aplastamiento de valores e ideales por parte de la dictadura. Daniel Molina (1987) ${ }^{10}$ participa en varias de estas publicaciones y en Fin de Siglo confecciona un diagnóstico de la producción cultural; encuentra que "no hay nostalgia: la nueva cultura se está produciendo ya: una nueva subjetividad se encuentra en marcha” (p. 71). Frente a ello se pregunta dónde ocurre: "un poco por todas partes, sin lugar fijo. Aún no se lo percibe porque su imagen es de perfil y su cuerpo, la viscosa intensidad del deseo" (Molina, 1987, p. 71). No es "un simple rostro de oposición” ni “el negativo de lo otro" porque "vive en las grietas, agrieta los muros, estalla en los intersticios" (Molina, 1987, p. 71). Molina puede anclar esa "viscosidad", entre la enumeración que detalla, en la literatura Aira. Además, en estas publicaciones hay otra constante: un conjunto de colaboradores que son cercanos a Aira. Me refiero a su vínculo con sus pares y amigos, como Rodolfo Fogwill, Tamara Kamenszain y Arturo Carrera. Se trata de un círculo de sociabilidad que Héctor Libertella (2006) denomina "salón literario", y que se forja desde la década de los setenta. Kamenszain (2018) lo recuerda como un "círculo cerrado" compuesto por escritores de entre veinte y treinta años que intercambian

\footnotetext{
10 Molina es uno de los primeros lectores entusiastas de Aira. Es "productor de la época, suerte de hombre-nido de esos que aparecían en un segundo plano, pero que daban lugar a los que no tenían lugar y ahora lo tienen [...] gay con megáfono y ex preso político, una suerte de protagonista de El beso de la mujer araña compactado en un solo personaje" (Moreno, 2003). Su participación en los circuitos culturales de los años ochenta es profusa desde que recupera su libertad. Porque desde 1974 Molina está preso tras ser acusado de un delito mientras presta el servicio militar. Era militante del Partido Revolucionario de los Trabajadores, brazo político del Ejército Revolucionario del Pueblo (Molina, 2012). Cuando lo liberan en 1983 comienza a estudiar letras, se incorpora en la redacción de revistas como El Porteño y Fin de Siglo, dirige el ciclo Inaudita que busca "difundir textos de la nueva escritura argentina, alejados del mercado de la edición comercial o de la difusión masiva" en la sala Miguel Cané de la Secretaría de Cultura de la Nación. Allí leen textos Laiseca, Leónidas Lamborghini, Carrera, Fogwill, Perlongher (La colmena, 1986, p. 7). Y pasará a formar parte del Centro Cultural Ricardo Rojas, un espacio vital para la producción artística y literaria de los años ochenta y noventa de Buenos Aires, donde Aira también circulará.
}

Hallazgos

ISSN: 1794-3841 | e-ISSN: 2422-409X | DOI: https://doi.org/10.15332/2422409X

Vol. 18 N.o 36| julio-diciembre del 2021 
sus propias producciones y críticas. Conforman, sostiene Kamenszain, lo que posteriormente se conocerá como taller literario. Estos escritores comparten una intensa vida literaria y ocupan posiciones marginales del campo en los setenta y comienzos de los ochenta (Riveiro, 2020). Se trata de un capital social que explica los primeros contactos de Aira con editoriales y su participación en estas publicaciones en particular.

\section{El polígrafo: los textos}

En 1988, Lucio Schwarzberg ${ }^{11}$ describe a Aira como un "polígrafo" que se define en oposición a la figura del "especialista" (p. 18) en el marco de una discusión sobre la "generación ausente" (Rubinich, 1985), noción que forma parte de una reflexión sobre intelectuales durante la transición democrática. En el único número de la revista Los Días del Viaje, Schwarzberg (1988) señala un fenómeno por el cual los intelectuales -que comienzan a ocupar puestos en centros de investigación, instituciones educativas y, en particular, la universidad tras las expulsiones y censuras de la dictadura cívico-militar- "pasaron de ser opositores políticos y culturales a instalarse en el oficialismo cultural (por lo menos) sin perder los hábitos de su juventud abruptamente perdida" (p. 17). Todo parece llevar a la "muerte intelectual" (1988, p. 17). En medio de esta "asfixia" en la que reina la figura del "especialista”, Schwarzberg encuentra en Aira "un punto de fuga" que parece dar con la solución: "ensayar. Ensayar sobre todas las cosas" (p. 18).

\footnotetext{
11 En 1984, como director de Cultura de la Universidad de Buenos Aires, funda el Centro Cultural Ricardo Rojas, que reúne a escritores y artistas como al propio Aira. La directora de Actividades Extracurriculares del Rojas es Tamara Kamenszain, amiga de Aira, quien lo invita a dar un curso sobre Copi, cuando gran parte de la obra del autor no circula en Argentina ni incluso está traducida al castellano. Aira dicta los cursos Cómo Leer a Copi (1988) y Alejandra Pizarnik (1996) en el ciclo Cómo Leer a Fin de Siglo. Las transcripciones del primero se publican en 1991 (Copi) y del segundo en 1998 (Alejandra Pizarnik), ambos casos en Beatriz Viterbo.
} 
Tomo esta categoría nativa de "polígrafo" para convertirla en una categoría analítica y ordenar conceptualmente los datos que construyo a partir de los textos de Aira que aparecen en publicaciones periódicas en los años ochenta. En sus textos, Aira plantea temas variados que desbordan lo literario, como el feminismo y la televisión. Ello, argumento, contrasta con la imagen de escritor puro que concibe la literatura como un ámbito por completo separado de cualquier otra dimensión de la vida y con la que se presenta Aira (Riveiro, 2019). No obstante, también es posible rastrear una misma línea o mirada que recorre esos diversos temas: una noción particular de la literatura que puede abordarlo todo sin las exigencias de otros tipos de conocimientos.

En sintonía con las propuestas de las publicaciones en las que participa, los temas de los textos de Aira efectivamente no se restringen a la narrativa argentina y latinoamericana, sino que también abordan la poesía ("Tres maestros", El Porteño, 1985), las discusiones sobre intelectuales ("Sin novedad en el frente", El Porteño, 1986; "Abril es un mes razonablemente cruel”, Creación, 1986; "El discurso del ‘posmodernismo”, Creación, 1986), la traducción (“Encuesta: la traducción poética”, $X u l, 1982)$, y temas que exceden lo estrictamente literario, como la inteligencia artificial y la televisión ("Sobre la inteligencia artificial”, El Porteño, 1986; “¿La civilización de la imagen? De Fellini a García Márquez [con escala en la televisión]”, El Porteño, 1986). Incluso opina sobre feminismo cuando participa de un cuestionario sobre el tema en un artículo titulado "El feminismo debe tomar la vía del terror", publicado en 1986 en el suplemento cultural del diario Tiempo Argentino. Aira también publica reseñas breves de libros publicados o traducidos de manera contemporánea, tanto de ficción como de corte ensayístico ${ }^{12}$.

\footnotetext{
12 En su mayoría son reseñas breves de libros publicados o traducidos de manera contemporánea, como Alguien que anda por ahí de Julio Cortázar ("Cortázar, Puig:
}

Hallazgos

ISSN: 1794-3841 | e-ISSN: 2422-409X | DOI: https://doi.org/10.15332/2422409X 
En estas asiduas intervenciones, a pesar de estar atadas a cuestiones o ediciones coyunturales, encuentro que los diversos temas pasan por un mismo tamiz. Los argumentos aportan a una noción particular de la literatura que puede abordarlo todo, pero sin las exigencias de otros tipos de conocimientos. Un gesto que se repite es el cambio de foco en relación con el tema anunciado en el título. En ocasión de responder a una encuesta sobre la traducción de poesía, Aira propone que "en la extensión del concepto de traducción literaria a la idea general de traducción está el fundamento de la soberanía de Estado. El sentido, cuyo respaldo y garantía es la traducción, nos hace dóciles ante la ley" (Aira i, 1982, p. 8). En un texto sobre intelectuales, que escribe al lado de la opinión de Horacio González, desestima rápidamente el eje de la discusión porque afirma no tener "noticias ciertas sobre la existencia de intelectuales en la Argentina" (Aira i, 1986a, p. 60). Así pasa a formular "algunas opiniones sobre la literatura actual en la Argentina" (Aira i, 1986a, p. 60) y propone

conjurar la realidad argentina", Vigencia, 1981), El evangelio apócrifo de Hadattah por Nicolás Peyceré ("Reseña", Vigencia, 1981), Paisajes de Luis O. Tedesco ("Reseña", Vigencia, 1981), Las viejas fantasiosas de Elvira Orphée ("Reseña", Vigencia, 1981), Lejos de África y Sombras en la hierba de Isak Dinesen ("Hechizo y memoria de una ausente", Creación, 1986), Recuerdos de Polonia de Witold Gombrowicz ("Nostalgias de un polaco en el exilio", Creación, 1986), Existenciales de Alberto Girri y Maquiavelo historiador de José Luis Romero ("Novedades", Creación, 1986), Circus de Leónidas Lamborghini, Magra, pero no mucho, las piernas fuertes, morena de Antonio Carlos Resende y Memorias de Charles Maurice de Talleyrand ("Reseña", Creación, 1986), Sólo los elefantes encuentran mandrágora de Armonia Somers ("Para becarios norteamericanos, esa peste", Fin de siglo, 1987), El mago de John Fowles ("Cómo es posible el amor entre un hombre y una mujer", Fin de Siglo, 1987), El hechizo de Elsie de Patricia Highsmith ("Indiferente como la realidad", Fin de Siglo, 1987), Primavera sombría. El hombre jazmín de Unica Zürn ("Loca y con talento", Fin de Siglo, 1987), Ensayos generales sobre el barroco de Severo Sarduy ("Un escolar aplicado", Fin de Siglo, 1988), iMinga! de Jorge Di Paola ("El deseo de viajar", Fin de Siglo, 1988), Foucault y la ética de Tomás Abraham ("Indiferente como la realidad", Fin de Siglo, 1988), El bosque de la noche de Djuna Barnes ("La artilla anticipada de lo nuevo", Fin de Siglo, 1988) y La hija de Kheops de Alberto Laiseca ("Una máquina de guerra contra la pena", Babel. Revista de libros, 1989). Incluso escribe otras reseñas bajo el seudónimo de Alicia Vallejos (Contreras, 2002): Sobre sus párpados abiertos caminaba una mosca de Dalmiro Sáenz y El zorro. Inglaterra mía de D. H. Lawrence y ("Reseña", Creación, 1986).

Hallazgos

ISSN: 1794-3841 | e-ISSN: 2422-409X | DOI: https://doi.org/10.15332/2422409X

Vol. 18 N.o 36| julio-diciembre del 2021 
"para los que estén descontentos con este estado de cosas, volver a algo tan viejo y desacreditado como la vanguardia" (Aira i, 1986a, p. 60).

En el texto a propósito del fallecimiento de Simone de Beauvoir, concluye con la siguiente reflexión: "Si el intelectual de izquierda fue el hombre más feliz hace unos veinte años, este fin de siglo quedará marcado por la lenta creación de una nueva felicidad" (Aira i, 1986b, p. 75). Tras ello, cierra el artículo con una reivindicación a José Bianco. El debate sobre la inteligencia artificial dispara reflexiones acerca de los libros que abordan el tema enfocados, encuentra Aira, en la categoría de tiempo planteado "al modo proustiano" (Aira i, 1986c, p. 60). El suplemento de cultura de Tiempo Argentina elabora un cuestionario que presenta a escritores y críticos sobre la literatura femenina, la identidad de género, la imagen de las mujeres y la poética de varones. Aira parte por rechazar los términos en que se plantea la cuestión: "No creo que haya literatura femenina ni masculina" (Aira i, 1986d, p. 5). A partir de ello propone que la literatura "consiste en volverse mujer" como herencia de "estilo" y bien lejana, "incompatible", del "feminismo, la ecología, el marxismo, la religión, y en general todos los sistemas que promueven las buenas intenciones" (Aira i, 1986d, p. 5).

Más allá de la diversidad de autores y temas, entonces ¿qué valora Aira? Entre otros elementos, en Lamborghini, "la operación misma del paso de verso a prosa" (Aira i, 1987a, p. 26); la "gran poesía" de la surrealista Unica Zürn (Aira i, 1987b p. 55); de iMinga! de Jorge Di Paola destaca que es "un deseo de viajar, de desprenderse, de ser feliz (¿por qué no?); un deseo que se desplaza entre el autor y el lector, y no se asienta en ninguno" (Aira i, 1988a, p. 53). En contraste con "las figuras del escritor, el filósofo, el teórico, el visionario, el erudito", Aira opina que Severo Sarduy "sobrepone una que las incluye a todas y las eleva a una peculiar luz de felicidad, la del escolar aplicado, el hombre-niño que llena las páginas de su cuaderno lo 
mejor posible. Y él sabe hacerlo maravillosamente bien" (Aira i, 1988b, p. 63). En la reseña de La hija de Kheops, afirma "el trabajo de Laiseca no es la Historia, sino su contracara, la Felicidad. [...] la literatura en él es una máquina de guerra contra la Pena; si no puede construir Pirámides, puede crear exorcismos, y sabe hacerlos de veras grandes y eficaces" (Aira i, 1989, p. 4).

El último texto que encuentro correspondiente a este recorte temporal condensa la imagen de escritor que resalta una y otra vez Aira en estos años, y que contrasta con cualquier vinculación de la literatura con la política o el contexto sociohistórico, una imagen central como veremos en el apartado siguiente. En la revista Babel. Revista de Libros, Aira escribe sobre Emeterio Cerro para afirmar sin matices:

¿Qué son estos libritos sin pie ni cabeza que todo el mundo se apresura a descartar como glosolalias taradas y que hacen pensar siempre en el traje nuevo del emperador y en el snobismo pueril de los incapaces? Antes que todo lo demás, son un test. Una piedra de toque o prueba de fuego que revela a la gente que cree que la literatura puede ser una actividad inocua, o un deber escolar bien hecho, o un instrumento de prestigio; a los que creen que puede no ser un extremismo; que se puede ser artista y seguir perteneciendo a la sociedad, e incluso gozar de lo mejor de dos mundos. Que se puede ser un gran artista y no sufrir escarnios (iqué vivos!). La prueba funciona con un automatismo de chip. El que no ama a Emeterio no ama a la literatura, así de simple es. (Aira i, 1990, p. 41)

Estas afirmaciones le ganan dos respuestas que polemizan con él. En el número 20 de Babel. Revista de Libros, Ana María Shua (1990) rechaza "cualquier reglamento al que deba ajustarse un autor para ser admitido en el parnaso" (p. 7), tal como el que propone Aira, e impugna la posibilidad de realizar rupturas en el arte: "En cuanto a escandalizar, lo lamento: yo también quisiera, pero después de aquella simpática historia de los

Hallazgos

ISSN: 1794-3841 | e-ISSN: 2422-409X | DOI: https://doi.org/10.15332/2422409X

Vol. 18 N.o 36| julio-diciembre del 2021 
burgueses atacando feroces los cuadros impresionistas, ninguna reacción parecida ha vuelto a registrarse en el mundo del arte" (Shua, 1990, p. 7). Paradójicamente la respuesta que propone que ya no existen las provocaciones en arte parece estar confirmando el conflicto al proponer la polémica. C. E. Feiling (1990) también escribe una respuesta en la que no solo está en desacuerdo con la afirmación de Aira, sino que además desconfía de la posibilidad real de "escandalizar" (p. 7). Lee su postura como un gesto de "un romanticismo tardío e incurable" (p .7).

\section{Posiciones marginales y centrales}

La propuesta de Aira y la circulación de sus textos en estas publicaciones toma un sentido más claro cuando nos detenemos en otras posiciones y zonas que son significativas en su definición. Los textos antes citados circulan por zonas marginales del campo, mientras que en su centro se ubican debates entre intelectuales que, durante la transición democrática, tienen en común "una autocrítica previa" al "fundamento revolucionario que había legitimado las prácticas culturales durante los sesenta y los setenta" (Patiño, 2006, p. 715) -temas ajenos al foco de Aira como hemos visto-. Es posible estudiar las reformulaciones del papel del intelectual condensadas en una publicación central como Punto de Vista que, a diferencia de los espacios que habilitan la propuesta de Aira, es central en el campo, dado que ejerce la "condición de árbitro de los debates y consagrador de temas y escritores" (Patiño, 2006, p. 175).

Punto de Vista, desde una "hiperconciencia" (Patiño, 2006, p. 175), por un lado, realiza una renovación teórica con "una serie de iniciativas de importación y traducción de teorías y debates críticos (las lecturas de Raymond Williams y de Pierre Bourdieu, los estudios sobre cultura popular, sobre modernidad y sobre ciudad, entre los principales)" (Dalmaroni, 2010, p. 642); por el otro, presenta "una marcada preferencia 
por el arte y la literatura de vanguardia o 'altomodernista', ajena a los mandatos del mercado y disolvente respecto de los sistemas autoritarios de creencias culturales" (p. 642). Construye un nuevo paradigma de lectura que reprocesa los ejes ideológicos y políticos que permiten ampliar la mirada de la crítica y releer la tradición: "hay una clara relectura de Sarmiento, Borges y las vanguardias, una puesta en valor de temas demonizados por la crítica literaria de izquierda desde que la revista Contorno le había arrebatado la hegemonía crítica a la cultura liberal representada por Sur" (Patiño, 2006, p. 175).

Con estas relecturas, y con el nuevo marco teórico, la crítica literaria de Punto de Vista comienza a focalizarse, en particular, en la literatura de Juan José Saer. Mientras que sus primeros libros, publicados en los sesenta, parecen "ilegibles" o "insatisfactorios" (Dalmaroni, 2010, p. 613), en los años ochenta se vuelven un objeto privilegiado de la revista que va a formar parte de su creciente consagración. La obra de Saer impide "una lectura previsible, la lectura política o histórica, es decir, el simplismo realista o referencial" (p. 633), según define Dalmaroni, citando a Beatriz Sarlo en una de las lecturas de principios de los ochenta.

El "carácter político de la función de la literatura”, eje del campo literario en los setenta, no se rechaza pero se traduce en su "especificidad literaria" (Saítta, 2004, p. 245). Tales sentidos son fuertes para leer la literatura de estos años. No obstante, no parece ser la matriz de lectura más afín a la propuesta que viene delineando Aira, aunque incluso se llega a leer su obra en esta clave -lectura que parece imponerse dejando de lado lo particular de su propuesta - . Noemí Ulla comenta que "la parodia constituyó una forma de respuesta al estado de censura en que se vivía" ("Segundo Encuentro de Escritores Dr. Roberto Noble”, 1989, p. 6) y ejemplifica esa 
idea con Ema, la cautiva de Aira y Matando enanos a garrotazos de Laiseca ${ }^{13}$.

En los artículos de estos años que circulan en publicaciones periódicas, Aira enfatiza la mirada que separa lo literario de cualquier tipo de vínculo con lo social. Esto es claro en el modo en que justamente lee a Saer. Es uno de los dos novelistas "presentables" (Aira i, 1987c, p. 67), no por su tensión con otras lógicas o su reformulación del vínculo con la política, sino por la técnica y el estilo:

En un continente donde lo característico es escribir algo realmente bueno a los veinte años, y después dedicarse a declinar, Saer es un europeo.

Salvo que, al mismo tiempo y a diferencia de un europeo, ese transcurso progresivo lo vuelve el eterno aprendiz, y pone la técnica, en sentido amplio, en primer plano. Mientras el estilo de un europeo es su persona, el de un americano es su trabajo. (Aira i, 1987c, p. 67)

\section{En un frecuentemente citado artículo publicado en Vigencia, Aira comienza por afirmar que}

[...] la novela argentina actual, quién lo duda, es una especie raquítica y malograda. En líneas generales, lo que define a una producción novelística pobre es el mal uso, el uso oportunista, en bruto, del material mítico-social disponible, es decir de los sentidos sobre los que vive una sociedad en un momento histórico dado. (Aira i, 1981, p. 55)

\footnotetext{
${ }^{13}$ Si bien la cuestión de la recepción de la obra de Aira excede los límites de este artículo, resulta relevante citar brevemente el modo en que la crítica de Punto de Vista lee los primeros libros de Aira, dado que esclarece el contraste de su propuesta literaria con los valores compartidos por dicha publicación. María Teresa Gramuglio reseña Ema, la cautiva y Nora Catelli, Canto Castrato, y mientras que ambas rescatan elementos valiosos en las novelas, se encuentran con faltas en la obra de Aira: queda "atrapado - cautivado- en su propia seducción: encuentra sus límites - su fronteraen la parcialidad de un gesto que hace de la exacerbación del juego inventivo la clave de su diferencia con otras tendencias narrativas coexistentes y posibles" (Gramuglio, 1982, p. 28) y la invención de su literatura aparece como "debilidad" (Catelli, 1983, p. 37).
} 
En el mismo tono escribe sobre el tema de los intelectuales y menciona en particular Punto de Vista:

He creído notar (subliminalmente, por supuesto, porque no leo nada de literatura argentina actual) un cierto movimiento de parálisis en nuestras letras, o la voluntad de preservar el status quo, lo que resulta esencialmente anti-literario. Yo diría que uno de los motivos, dependiente a su vez de un desmedido desprecio al trabajo, está en la promoción que vienen haciendo los más respetados faros del establishment cultural (la revista Punto de Vista por ejemplo) de una postura autocrítica, y de crítica de la autocrítica, y así sucesivamente, en cuyos infinitos prolegómenos debería detenerse para siempre la actividad del aspirante a escritor. Pero debo reconocer que este purgatorio, con su inevitable secuela de esterilidad, es preferible a la alternativa que representan las novelas escritas en la Argentina en los últimos diez años. Después de todo, hay cosas peores que la parálisis. (Aira i, 1986a, p. 60)

Se precisará una renovación en los términos en los que se piensa la literatura para poder leer y valorar a Aira (Riveiro, 2020). ¿Cuáles son las condiciones para que ello ocurra? Una publicación como Babel. Revista de Libros (1988-1991) anticipa los espacios diferentes por los que comenzará a circular Aira en los años noventa ${ }^{14}$. Entre la segunda mitad de los años ochenta y la primera de los noventa, cuando se percibe una "segunda transición cultural” (Patiño, 2006), se corren los términos en que está

\footnotetext{
${ }^{14}$ Babel. Revista de libros (1988-1991) es una publicación de la que salen 22 números. Los primeros cuatro números están financiados por la Cooperativa de Periodistas Independientes, aquella que en 1985 retoma la publicación de El Porteño. A partir del número 6 la edita Puntosur. Integrantes de la revista son Alan Pauls, Sergio Chejfec, Luis Chitarroni, Daniel Guebel, Ricardo Ibarlucía, Diego Bigongiari y Daniel Samoilovich. El grupo editorial se presenta bajo el nombre de Shanghái. Tiene gran impacto en el campo literario, lo que se debe, en parte, a la efectividad de su presentación en público (Castro, 2015). Para presentarse como grupo Shanghái publican un manifiesto en El Porteño, en Diario de Poesía y en Página/12. Pero más lejos del gesto vanguardista que indica el manifiesto, presentan el primer número de la revista en el evento más tradicional del mundo literario como lo es la Feria del Libro en su XIV edición, el 8 de abril de 1988.
}

Hallazgos

ISSN: 1794-3841 | e-ISSN: 2422-409X | DOI: https://doi.org/10.15332/2422409X

Vol. 18 N. 0 36| julio-diciembre del 2021 
planteado el debate literario e intelectual en el momento que comienza a reinar la sensación de desencanto por la primavera democrática. Entran en crisis los acuerdos sobre el renovado papel del intelectual en democracia. Se habilita la posibilidad de pensar las producciones culturales y literarias en sus propios términos; de forma ajena a la noción de utilidad, se acercan a la posibilidad del goce ${ }^{15}$.

De manera simultánea, en la carrera de Letras de la Facultad de Humanidades y Artes de la Universidad Nacional de Rosario se está modificando el plan de estudios de la carrera y hay un cambio rotundo en las lecturas. Algunos egresados ingresan al plantel docente con una mirada renovada y la búsqueda por lo nuevo en la literatura, y Aira aparece como una novedad. Alberto Giordano, Sandra Contreras, Marcela Zanin, Adriana Astutti, Nora Avaro, entre otros críticos y licenciados en letras, diseñan programas, organizan jornadas y cursos en los que incorporan a Aira como su objeto de estudio, así como invitado que dicta cursos o lee ponencias en los congresos ${ }^{16}$. A su vez, fundan publicaciones como Paradoxa. Literatura/Filosofía y el Boletín del Grupo de Estudios de Teoría Literaria, en el que Aira participará de manera asidua con textos que, como se trata de publicaciones universitarias, adoptan otras formas más cercanas al ensayo que a la reseña, que sí escribe de manera asidua, como vimos, a principios de los años ochenta.

Este artículo reconstruyó las condiciones de posibilidad para la circulación de los textos tempranos de Aira en publicaciones periódicas que, como el texto viene delineando y a diferencia de la centralidad que alcanzará Aira

\footnotetext{
${ }^{15}$ Cuando Babel elige Los fantasmas como "Libro del mes", Pauls (1990) escribe que Aira "postula dos sentidos a la vez sin decidirse por ninguno [...] El goce lunático de la paradoja es la verdadera fiesta de Los fantasmas" (p. 5). Lejos de entablar una relación crítica con la realidad o de producir conocimiento, "una novela se escribe con verdades de Perogrullo, con la pulida estupidez del sentido común" (p. 5).

16 En Rosario, Aira también encontrará un espacio donde publicar sus libros. Me refiero a la editorial Beatriz Viterbo, creada en 1991 por Astutti, Contreras y Zanin.
}

Hallazgos

ISSN: 1794-3841 | e-ISSN: 2422-409X | DOI: https://doi.org/10.15332/2422409X 
en los años venideros, son revistas y suplementos de las zonas marginales del campo literario. Esta posición se puede observar mediante el análisis de las características materiales de las publicaciones, así como mediante la definición relacional con otros espacios. Mientras que estas zonas habilitan la circulación de textos de Aira, habrá que esperar para que la crítica lea su obra y su producción de manera favorable. Publicaciones creadas a fines de los años ochenta y comienzos de los noventa, así como grupos de investigación, sobre todo en la Universidad de Rosario, renovarán los criterios de la crítica y en ese movimiento valorarán la obra de Aira. Esos espacios también se abrirán para la publicación de sus textos. Sin embargo, su análisis excede el alcance de este artículo, dado que tienen características particulares y las condiciones de producción y circulación de la literatura de Aira son distintas, por lo que pasaremos a las reflexiones finales.

\section{Conclusiones}

En este artículo me concentro en la trayectoria temprana de César Aira para estudiar los espacios que se abren a sus textos cuando es un escritor recién editado. Encuentro que, en contraste con el reconocimiento que recibirá de la crítica sobre todo a principios del siglo XXI, en los años ochenta son las publicaciones periódicas que no se centran en particular en la literatura las que habilitan sus producciones. Esto se puede explicar dado que los debates centrales del campo literario giran en torno a ejes como las redefiniciones de los vínculos entre política y literatura que Aira rechaza. En paralelo, en el marco de la transición democrática, numerosas publicaciones marginales en función de los debates literarios, en sintonía con el clima de apertura, habilitan la incorporación de propuestas disruptivas. Es en estas publicaciones donde, además, participan actores 
cercanos al círculo de sociabilidad de Aira, lo que permite vislumbrar el capital social con el que cuenta al ingresar al campo.

Con este análisis de un caso particular como el de la trayectoria de Aira, me propuse revalorizar la complejidad del hecho literario cuya comprensión se ve enriquecida con el estudio de dimensiones a menudo soslayadas. La mirada sensible a las dimensiones sociales de la literatura suele enfocarse en actores como el público o en los elementos ideológicos de las obras. Este artículo buscó ser un aporte al estudio de la producción literaria al visibilizar y analizar producciones de escritores en publicaciones periódicas, con un especial hincapié en su materialidad. Es decir, el foco estuvo puesto en los circuitos, las características de las publicaciones y las zonas del campo que ocupan, dado que son cuestiones vitales para dar cuenta y comprender las transformaciones dentro de una trayectoria.

A su vez, busco evitar las miradas retrospectivas que obstaculizan el estudio histórico e impiden dar cuenta de las diversas condiciones de posibilidad para la emergencia de posiciones novedosas como la de Aira. De este modo, por ejemplo, discuto con el sentido común cristalizado sobre Aira de que se trata de un "escritor silencioso" que no participa de instancias públicas. Sin lugar a dudas, a mediados de los años noventa deja de dar entrevistas a medios de comunicación hasta comienzos del siglo XXI. Sin embargo, en los años ochenta su participación en distintas instancias es profusa. Una de ellas son las publicaciones periódicas, tal como se pudo vislumbrar en los textos citados que son fuentes poco exploradas hasta el momento. Más allá del valor de estos escritos que corresponden a un autor reconocido en los inicios de su trayectoria, son fuentes relevantes para el estudioso, dado que habilitan la pregunta sobre las condiciones de posibilidad para la emergencia de una figura como la de Aira, que por años recibe rechazos dentro del campo literario. El estudio 
de estos textos es vital para indagar en los comienzos de la trayectoria de Aira y para dar cuenta de las condiciones de posibilidad y de los espacios habilitados para ella que, durante esos años, parecía improbable.

Las herramientas detalladas permiten construir un objeto de la literatura desde la sociología, y aprehenderlo como una práctica social con todas las determinaciones sociales e históricas que ello involucra. Estas determinaciones no se traducen en un vínculo mecánico que se opone a la libertad creadora que se le adjudica a la así llamada creación artística. Adscribo a una apuesta de las ciencias sociales que, a partir del estudio de la práctica artística como producto histórico social, lejos de acotar sus sentidos, enriquezca su conocimiento. Norbert Elias, en su estudio sobre Mozart y la producción de música, advierte:

Por lo general, se concibe a la sociología como una ciencia reductora y destructiva. Yo no comparto esta concepción. Para mí, la sociología es una ciencia que nos ha de ayudar a explicar y comprender mejor lo incomprensible de nuestra vida social. En este sentido he escogido el subtítulo aparentemente paradójico ‘Sociología de un genio’. Mi objetivo, por tanto, no es destruir o reducir al genio, sino hacer comprensible su situación humana y quizá también ofrecer una modesta aportación para dilucidar la cuestión de qué habría que hacer para evitar un destino como el de Mozart. Cuando se expone su tragedia tal como yo lo intento hacer -y esto solo es un ejemplo de un problema más amplio- quizá se pueda reforzar la conciencia del ser humano de que ha de ser más cauto con respecto a lo más nuevo. (Elias, 1991, p. 24)

En el caso de este artículo, en particular, la pregunta por la participación de Aira en publicaciones periódicas cuando es un escritor recientemente editado se propone, por un lado, enriquecer el conocimiento sobre este escritor y, por el otro, dar cuenta de las condiciones que hicieron posible su empresa en sus inicios, no exenta de numerosos obstáculos. 


\section{Sobre la autora}

María Belén Riveiro. Licenciada en Sociología y Doctora en Ciencias Sociales por la Universidad de Buenos Aires. Becaria posdoctoral del Conicet, con sede de trabajo en el Instituto de Investigaciones Gino Germani de esta universidad, donde además es docente de Sociología General. Miembro del "Grupo de Estudios de Sociología de la Literatura" (IIGG-UBA) y del "Programa Mundo editorial, lectura y traducción desde los estudios de género(s) y feminismos" (Laboratorio Interdisciplinario de Ciencias Humanas - Conicet). Su tesis doctoral aborda, desde la sociología de la literatura, la producción literaria argentina de la década de los años ochenta y noventa del siglo XX, enfocada en la reconstrucción de la trayectoria del escritor César Aira, para preguntarse por los procesos de dominación que subyacen al campo literario. Sus principales áreas de interés son la sociología de la literatura y de los bienes simbólicos. Actualmente trabaja la circulación internacional de los libros de Aira a través de las traducciones al inglés publicadas en Estados Unidos, y al francés, en Francia, dada la jerarquía de los idiomas y las redes entre editoriales a escala trasnacional. Algunos de sus artículos más recientes son: "Trayectorias editoriales inversas: escritores argentinos de narrativa entre fines del siglo XX y comienzos del siglo XXI” (2018, Badebec. Revista del Centro de estudios de teoría y crítica literaria), "César Aira en entrevistas: la construcción de la figura de escritor (1981-2001)” (2019, Trabajo y Sociedad) y "Ada Korn editora: por una historia crítica del mundo editorial" (2020, Cuadernos del Centro de Estudios en Diseño y Comunicación).

\section{Referencias}

Aira, C. (1982). "Yo nunca usaría la literatura para pasar por buena persona". Entrevista realizada por A. Castro y B. Borgna. Pie de Página, 1(1), 2-3. 
Aira, C. (1984, 11 de octubre). "Solo aspiro a una gloria de bolsillo". Charla con el escritor argentino César Aira. Entrevista realizada por D. Sperling. Cultura y Nación. Clarín, 1-2.

Aira, C. (1991, 12 de junio). "Todo escritor inventa su idioma”. César Aira: literatura y paradojas. Entrevista realizada por H. Pomeraniec. Cultura y Nación. Clarín, 1-3.

Aira, C. (2001). "Quisiera ser un salvaje”. Entrevista realizada por E. Berti. 3 punto, 5(227), 62-63.

Aira, C. (2004, 18 de abril). "Prefiero siempre lo nuevo a lo bueno". Entrevista realizada por R. Garzón. Cultura. El País.

http://elpais.com/diario/2004/04/18/cultura/1082239201 850215.html

Aira, C. (2005, 27 de junio). "El artista puede ser un criminal”. Entrevista realizada por X. Aiyén. La Nación.

http://www.lanacion.cl/noticias/cultura-y-entretencion/el-artista-puede-ser-un-cr iminal/2005-06-26/203335.html

Aira, C. (2007). Entrevista a César Aira. Realizada por L. Dapelo. Hispamérica, 36(107), 41-53. http://www.jstor.org/stable/20540779

Aira, C. (2016, 24 de junio). César Aira: "Leyendo novelas no se aprende nada”. Entrevista realizada por J. Rodríguez Marcos. Babelia, El País. https://elpais.com/cultura/2016/o6/23/babelia/1466689420_025152.html

Astutti, A. (1997). Un niño en la biblioteca nacional. Revista de Letras, (5), 37-43.

Boschetti, A. (2014). Ismes. Du realisme au postmodernisme. París: CNRS Éditions.

Bourdieu, P. (2005 [1992]). Las reglas del arte. Génesis y estructura del campo literario. Anagrama.

Bourdieu, P. (2007 [1981]). El sentido práctico. Siglo XXI.

Bourdieu, P. y Wacquant, J. D. (1995 [1992]). Respuestas. Por una antropología reflexiva. Grijalbo.

Castro, M. V. (2015). La producción novelística de la "generación ausente" en el contexto de las memorias del pasado reciente argentino (1973-1983) (tesis de doctorado). Facultad de Humanidades y Ciencias de la Educación, Universidad Nacional de La Plata. http://www.memoria.fahce.unlp.edu.ar/tesis/te.1239/te.1239.pdf

Catelli, N. (1983). La vuelta a la narración. Punto de Vista, 6(18), 38-40.

Hallazgos

ISSN: 1794-3841 | e-ISSN: 2422-409X | DOI: https://doi.org/10.15332/2422409X

Vol. 18 N.o 36| julio-diciembre del 2021 
Chacón, P. y Fondebrider, J. (1998). La paja en el ojo ajeno. Periodismo cultural argentino (1983-1998). Colihue.

Contreras, S. (2002). Las vueltas de César Aira. Beatriz Viterbo.

Dalmaroni, M. (2010). El largo camino del "silencio" al "consenso". La recepción de Saer en la Argentina (1964-1987). En J. J. Saer y J. Premat (Coords.), Glosa. El entenado. Edición crítica (pp. 607-663). Université de Poitiers-Alción.

De Diego, J. L. (2007 [2003]) ¿Quién de nosotros escribirá el Facundo? Intelectuales y escritores en Argentina (1970-1986). Ediciones Al Margen.

Editor. (1986). Por qué creación. Creación 1(1), 1.

Elias, N. (1991). Mozart. Sociología de un genio. Península.

Estrín, L. (1999). César Aira. El realismo y sus extremos. Ediciones del Valle.

Feiling, C. (1990). Esa clase de sed. Babel. Revista de Libros, 2(21), 5.

Fernández, N. (2000). Narraciones viajeras. César Aira y Juan José Saer. Biblos.

Franco, M. (2018). El final del silencio. Dictadura, sociedad y derechos humanos en la transición (Argentina, 1979-1983). Fondo de Cultura Económica.

Galperín, K. (1992). Ya no cautiva. V de Vian, 2(8), 14-15.

García, M. (2006). Degeneraciones textuales. Los géneros en la obra de César Aira. Beatriz Viterbo Editora.

Gramuglio, M. T. (1982). Increíbles aventuras de una nieta de la cautiva. Punto de Vista, (14), 27-28.

Hernaiz, S. (2012). Rodolfo Walsh no escribió Operación Masacre y otros ensayos. 17grises.

Kamenszain, T. (2018). El libro de Tamar. Eterna Cadencia.

Korn, G. (2019). Fin de Siglo. Archivo histórico de revistas argentinas. https://www.ahira.com.ar/wp-content/uploads/2019/12/Korn-Fin-de-Siglo-1.pdf

La colmena. (27 de julio de 1986). Tiempo cultura. Tiempo argentino, 7.

Laddaga, R. (2001). Una literatura de la clase media: notas sobre César Aira. Hispamérica, 3o(88), 37-48.

Libertella, H. (2006). La arquitectura del fantasma. Una autobiografía. Santiago Arcos.

Hallazgos

ISSN: 1794-3841 | e-ISSN: 2422-409X | DOI: https://doi.org/10.15332/2422409X

Vol. 18 N.o 36| julio-diciembre del 2021 
Margiolakis, E. (2014). La conformación de una trama colectiva de publicaciones culturales subterráneas durante la última dictadura cívico-militar argentina. Contenciosa. Revista sobre Violencia Política, Represiones y Resistencias en la Historia Iberoamericana, 1(2), 1-13.

http://bibliotecavirtual.unl.edu.ar/publicaciones/index.php/Contenciosa/article/v iew/5060/7700

Martínez, A. T. (2007). Pierre Bourdieu: razones y lecciones de una práctica sociológica. Del estructuralismo genético a la sociología reflexiva. Manantial.

Milanesio, N. (2019). Destape: sex, democracy, and freedom in postdictatorial Argentina. University of Pittsburgh Press.

Molina, D. (1987). La viscosa intensidad del deseo. Fin de Siglo, (2), 71.

Molina, D. (2012, 3 de marzo). Empecé a morir en las cárceles de la dictadura. Clarín. https://www.clarin.com/sociedad/titulo_o_By8xonI3PQg.html

Montaldo, G. (1998). Borges, Aira y la literatura para multitudes. Boletín, (6), 7-17.

Moreno, M. (2003, 28 de diciembre). La generación del ochenta. Radar, Página/12. https://www.pagina12.com.ar/diario/suplementos/radar/9-1149-2003-12-28.html

Otero, J. M. (1990). 30 años de revistas literarias argentinas (1960-1989). Introducción a su estudio. Catedral al Sur Editores.

Patiño, R. (1997). Intelectuales en transición. Las revistas culturales argentinas (19811987). Cuadernos de Recienvenido, 4. Universidad de San Pablo.

Patiño, R. (2006). Revistas literarias y culturales argentinas de los 80: usinas para pensar una época. Ínsula, (715-716). https://www.insula.es/sites/default/files/articulos muestra/INSULA\%20715716.htm

Pauls, A. (1990). El revés del sentido. "Los fantasmas". Babel. Revista de Libros, 2(21), 5.

Premat, J. (2005). El idiota de la familia. En M. Lafon, C. Breuil y M. Remón-Raillard (Eds.). César Aira, une révolution (pp. 79-86). Tigre/Hors série-Cerhius (Ilcea)Univesité Stendhal-Grenoble 3-LI.RI.CO-TRAVERSES-Université Paris 8.

Remon-Raillard, M. (1999). César Aira o la literatura del continuo (tesis doctoral). Grenoble 3. 
Riveiro, M. B. (2018). La trayectoria temprana de César Aira en textos de publicaciones periódicas. X Jornadas de Sociología de la Universidad Nacional de la Plata, Facultad de Humanidades y Ciencias de la Educación Ensenada, 5, 6 y 7 de diciembre de 2018. http://jornadassociologia.fahce.unlp.edu.ar/xjornadas/actas/RiveiroPONmesa39.pdf

Riveiro, M. B. (2019). César Aira en entrevistas: la construcción de la figura del escritor (1981-2001). Trabajo y Sociedad, 2O(33), 83-101. https://www.unse.edu.ar/trabajoysociedad/33\%20RIBEIRO\%20BELEN\%20Cesar \%20Aira.pdf

Riveiro, M. B. (2020). La trayectoria de César Aira: la conformación de un centro descentrado en el campo literario de la ciudad de Buenos Aires (1981-2001) (tesis doctoral). Universidad de Buenos Aires.

Román, C. (1997). Revistas literarias de Buenos Aires en los años de la democracia (1983-1993). Universidad de Buenos Aires.

Rubinich, L. (1985). Retrato de una generación ausente. Punto de Vista. Revista de Cultura, 7(23), 44-46.

Rubinich, L. (1999). Los sociólogos intelectuales: cuatro notas sobre la sociología en los 6o. Apuntes de Investigación del CECyP, (4), 31-55.

Saítta, S. (Ed.). (2004). Lo que sobra y lo que falta en los últimos veinte años de la literatura argentina. Libros del Rojas.

Salvador, N., Gover de Nasatsky, M. y Ardissone, E. (1996). Revistas literarias argentinas, 1960-199o. Aporte para una bibliografía. Fundación Inca Seguros.

Schwarzberg, L. (1988). Elogio de la prosodia del maestro. Los días del viaje. Revista de Política y Cultura, (o), 15-18.

Segundo Encuentro de Escritores Dr. Roberto Noble. (1989, 9 de noviembre). Cultura y Nación. Clarín, 1-6.

Servelli, M. (2020). Vigencia: la trama cultural de una revista del "Proceso". Orbis Tertius, 24(30). http://www.memoria.fahce.unlp.edu.ar/art revistas/pr.11519/pr.11519.pdf

Shua, A. M. (1990). Contra todo test. Sobre la defensa de Aira a Emeterio Cerro. Babel. Revista de Libros, 3(20), 7. 
Sigal, S. (1991). Intelectuales y poder en la década del sesenta. Puntosur.

Strafacce, R. (2008). Osvaldo Lamborghini, una biografia. Mansalva.

Strafacce, R. (2018). César Aira, un catálogo. Mansalva

Tarcus, H. (2007). Catálogo de revistas culturales argentinas. 1890-2007. Cedinci.

Un antipremio a la poesía. (1987, 31 de diciembre). Página/12, 9.

Un banquete para la lectura. (2005, 24 de abril). La Nación. Cultura. http://www.lanacion.com.ar/697756-un-banquete-para-la-lectura

Warley, J. (1993). Revistas culturales de dos décadas (1970-1990). Cuadernos Hispanoamericanos, (517-519), 195-207.

Zito Lema, V. (1987). Adiós crisis. Fin de Siglo, (1), 2.

\section{Textos de Aira en publicaciones periódicas}

1981. Novela argentina: nada más que una idea. Vigencia, (51), 55-58.

1982. La traducción poética. Xul. Signo Viejo y Nuevo. Revista de Poesía, 4, 7 y 8.

1986a. Sin novedad en el frente. El Porteño, 5(51), 60.

1986b. Abril es un mes razonablemente cruel. Simone de Beauvoir; Genet, la izquierda, Bianco. Creación. La Revista Argentina para el Nuevo Siglo, 1(1), 74-75.

1986c. Sobre la inteligencia artificial. El Porteño, 5(57), 61-62.

7 de septiembre de 1986d. El feminismo debe tomar la vía del terror. Tiempo Cultura.

Tiempo Argentino, 5 .

1987a. De la violencia, la traducción y la inversión. Fin de Siglo, (1), 26.

1987b. Loca y con talento. Fin de Siglo, (5), 55.

1987c. Zona peligrosa. El Porteño, 6(64), 67-68.

1988a. El deseo de viajar. Fin de Siglo, (8), 53.

1988b. Un escolar aplicado. Fin de Siglo, (9), 63.

1989. Una máquina de guerra contra la pena. Babel. Revista de Libros, 2(12), 4.

1990. El test. Una defensa de Emeterio Cerro. Babel. Revista de Libros, 3(18), 41.

Hallazgos

ISSN: 1794-3841 | e-ISSN: 2422-409X | DOI: https://doi.org/10.15332/2422409X

Vol. 18 N.o 36| julio-diciembre del 2021 